\title{
Human resource management moral competencies
}

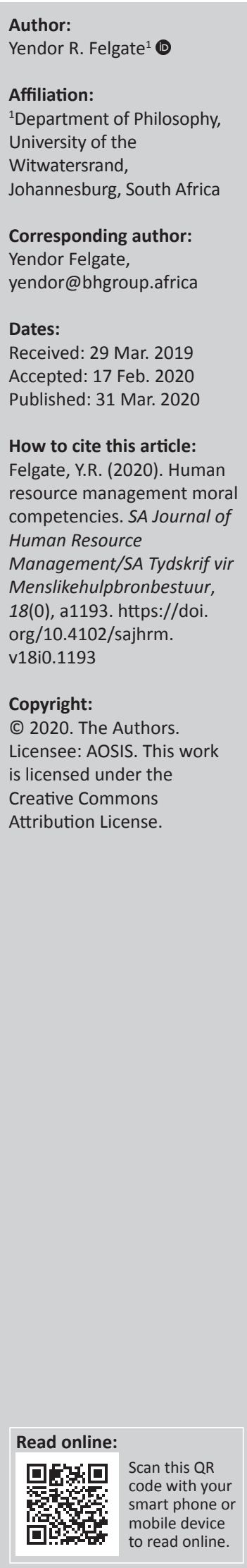

Orientation: If Human Resource Management (HRM) has a positive role in providing direction for the permissible use of people in organisations, then such a role inevitably creates a number of ethical tensions. The HRM practitioner often encounters situations, where they require moral expertise to make decisions that are ethical.

Research Purpose: The purpose of the research is to identify and describe the moral competencies HRM can use to make normative judgements in organisations.

Motivation for the Study: The understanding of HRM moral expertise is important, given the role of HRM in organisations.

Research Design: This article uses a virtue-ethical approach to identify and describe possible HRM moral competencies and their use.

Main Findings: There is value to using a virtue-theoretic approach in HRM, because it allows for the identification of moral competencies that can be used to improve ethical decision making, when using HRM practices.

Practical/Management Implications: The article provides a practical approach to using moral expertise. Moral expertise can be used to discern concrete normative actions when using HRM practices, and so doing improve normative outcomes for employees and organisations.

Contribution/Value Add: This is the first attempt to identify and apply HRM moral competencies to HRM decision-making and practice. Furthermore, if the requirement for HRM moral expertise is known, it follows that it can provide the basis for further HRM professional development.

Keywords: HRM; Virtue, Virtue as skill, HRM moral competencies; HRM decision-making; HRM practice; Performance Management.

\section{Introduction}

If human resource management (HRM) is given a positive role regarding the permissible use of people in organisations in the form of HRM policy-making, then HRM practitioners are still required to apply such policies or make ethical decisions in difficult cases, which inevitably create a number of ethical tensions. Human resource management practitioners often encounter situations where they have to use their judgement to make decisions that are ethical, as it is not always possible to resolve ethical tensions by merely resorting to accepted HRM practice or rules. It then follows that it is important to understand what type of ethical expertise HRM practitioners require to make dependable judgements. This article uses a virtue-ethical approach to identify and describe possible HRM moral competencies and their use in HRM decision-making.

Human resource management deals with complex normative issues regarding the legitimate use of people in organisations. Human resource management is commonly defined as the productive use of people in achieving the organisation's strategic business objectives and the satisfaction of individual employee's needs (Greenwood, 2002, p. 261). Many HRM practitioners recognise that HRM has an ethical role to play in organisations, placing an emphasis on such things as 'sound moral character' and the 'respect for human dignity' (Kirsten, Wordsworth, Van Niekerk, \& Erasmus, 2015). Few, though, are clear on how to define ethics or go about being ethical (Van Vuuren \& Eiselen, 2006).

In this article, the author assumes that because of the demands of the role of HRM, HRM practitioners are required to become practical experts (both in a technical and a normative sense), with the ability to express such expertise in the form of ethical judgement. If so, the 
focus of this article would be on one type of normative expertise that HRM practitioners require to make reliable ethical judgements. The author attempts to identify and describe HRM moral competencies that are possible forms of HRM normative expertise, and in order to do so, he uses a virtue-ethical approach to propose HRM moral competence and provide examples of such within an HRM work context.

\section{The requirement for human resource management moral expertise}

Human resource management practitioners require practical moral expertise, because it is not always easy to determine what is ethical in complex environments such as organisations. Discretion is often required when formulating, implementing or interpreting policies. The South African Board of People Practices (SABPP), for example, recognises the need for the capacity and the active use of ethical judgement during the application of HRM practice. It argues in the following manner (Abbott, 2015):

The formulation and interpretation of policies is not always straightforward and it is in these grey areas that an HR practitioner needs to be skilled at recognising an ethical issue, analysing it and finding an appropriate resolution, which is fair to all parties. Furthermore, policies often provide for discretionary powers to be exercised by executives, line managers and HR practitioners. Some rules many not be totally clear, and sometimes roles and responsibilities overlap or leave gaps resulting in conflicts. Sometimes also, a judgement needs to be made where one of the possible outcomes is to the advantage or disadvantage of the HR practitioner who is providing advice or support to line management. There are, therefore, many situations in organisations where the ethical judgement of HR practitioners may be tested. (p. 5)

Most professional HRM associations recognise the need for HRM practitioners to make ethical judgements when using HRM practices (Academy of Human Resource Development [AHRD], 1999; SABPP, 2014; Society for Human Resource Management [SHRM], 2012, 2016). However, when the globally accepted HRM competency models are surveyed (Lee \& Yu, 2013), the capacity for ethical judgement is not discussed in any meaningful way. If HRM practitioners require the capacity or need to develop the skill to make ethical judgements, then it follows that this requirement should be understood in more detail. One way of approaching the development of ethical judgement and its use by practical experts is through the application of virtue theory.

Over the last 30 years, there has been a resurgence of interest in the concept of virtue, virtue-related topics and virtue theory in applied ethics (Annas, 2015, p. 1). A virtue approach provides a theoretical framework capable of describing how a person could develop the skill required to make ethical judgements in context, which is part of the normative HRM project of 'knowing what to do' in a practical sense when formulating, implementing and interpreting HRM policies (in short, HRM practice). Human resource management practitioners do so by developing the requisite virtues as a form of moral skill or moral competence - taken in its simplest form, this is the capacity to make a skilled moral judgement according to a given context (Morales-Sanchez \& Cabello-Medina, 2015).

The author begins with a short account of the concept of 'virtue' and explains how virtues are understood as analogous to skill. Then, he uses the notion of moral competence to propose and describe HRM-specific moral competence in more detail before providing some practical examples of how these moral skills could be used in HRM decision-making.

\section{Virtue as a skill}

Virtue ethics is one of the three major approaches in normative ethics. When referring to a virtue or moral excellence (arête), such as justice, courage, charity or benevolence, typically two concepts are applied. These are phronesis [practical or moral wisdom] and eudaimonia [usually translated as happiness or flourishing; Hursthouse, 2013, p. 2]. A virtuous person, then, is one who acts virtuously, and a virtue is a character trait that a human being needs to flourish (Hursthouse, 1991).

When virtuous people respond courageously, for example, they wholeheartedly (as per their disposition) face and overcome difficulties for a good cause, as to act on the contrary would probably be perceived as cowardliness (Annas, 2015, p. 4). Such virtues are developed as a form of intelligent response to circumstances over time (Annas, 1995, 2011, 2015; Hursthouse, 2013; Stichter, 2007a, 2013, 2015). The process of learning a virtue is analogous to that of acquiring a practical skill (Annas, 1995, 2011, 2015; Stichter, 2007a, 2007b, 2013, 2015). Virtue and skill are analogous in the following ways: they are similar in terms of motivation in that they require effort or intentionality to develop; they develop in similar ways in that they are learnt; and they both are forms of mastery.

The virtue-as-skill approach has been referred to in recent literature as a form of moral competence. In their work on management skills, Morales-Sanchez and Cabello-Medina (2015) usefully provided a workable definition of moral competence, which has been used in the rest of the article. According to Morales-Sanchez and Cabello-Medina (2015), moral competence is a:

... [S]et of knowledge, skills and attitudes and abilities acquired through experience, which in fact facilitate the engagement in ethical behaviours in a specific job ... These moral competencies are nothing other than virtues, which are internal mental and will-related capacities acquired by the continuous development of ethical behaviours capable of responding in a consistent (i.e. across different conditions or situations), stable (i.e. through different times), and integrated (i.e. in accordance with other similar competences). (p. S166) 
Moral competence is dependent on the intentionality of the practitioners and their active engagement with the context that they operate in. This results in the continuous development of ethical behaviours over time that are consistent, stable and integrated. In other words, moral competence is a virtue that could be described in terms of behaviours that include attributes such as knowledge, attitudes and abilities within context.

Much in the same way that Morales-Sanchez and CabelloMedina (2015) identified moral competencies specific to line management, it should be possible to identify moral competencies for HRM. Moral competence in this sense is a virtue adapted to specific job demands. It makes sense then that HRM practitioners could respond intelligently to circumstances if they develop specific forms of virtues over time. Virtue then is a part of the skill set of HRM practitioners that enables a correct or normative response to situations that fall within the domain of HRM. Such virtues are ordinary in nature but are domain-specific to HRM in terms of their application. For example, HRM practitioners do not normally require courage in the face of physical danger but may require moral courage when it comes to questions of justice at the workplace. Human resource management practitioners may require courage when dealing with labour disputes, abusive managers or ensuring fair treatment of women regarding remuneration.

Human resource management virtue enables a correct or normative response to situations that fall within the domain of HRM. If so, the question arises as to the nature of HRM moral competence. On this premise, the author now describes HRM moral competence and then their use in HRM decision-making.

\section{Human resource management moral competence}

Identifying the virtues that are important to a profession such as HRM is more difficult than gaining acceptance of the idea that virtue is in-and-if-itself important. There is a strong claim dating back to Aristotle, Socrates and Plato that virtues are universal, with some being cardinal (i.e. core virtues; DeVettere, 2002; Morales-Sanchez \& Cabello-Medina, 2013). Such universality or commonality is also supported by modern research psychology (Dahlsgaard, Peterson, \& Seligman, 2005, p. 205).

The focus of this article is on cardinal virtues, as it is perceived that these virtues directly pertain to professional decisionmaking (Morales-Sanchez \& Cabello-Medina, 2013). A summary of the moral components of HRM expertise and how they contribute to HRM decision-making is provided in Table 1 . The cardinal virtues are practical wisdom, justice, self-control and courage, as they pertain to HRM. It is conceivable that additional virtues, such as honesty (Stichter, 2007b) should be added, but for our purposes, a short description of cardinal virtues will suffice.
The author has suggested above that HR practitioners should know as to when to be courageous amongst others, and the way to do so in virtue theory is to use judgement. The virtue of good judgement is called practical wisdom, which is the intellectual virtue of good deliberation (DeVettere, 2002; Mele, 2012; Morales-Sanchez \& CabelloMedina, 2013). Human resource management practitioners are able to normatively 'deliberate, decide and direct' (Devettere, 2002, p. 84) for themselves when using practical wisdom.

Practical wisdom is thought of as the origin of virtue, and in this way it is considered a meta-virtue. Practical wisdom is the intentional activity of 'discerning the truth' (DeVettere, 2002, p. 115) and by so doing justifying concrete action (Stichter, 2015) when it comes to seeking human flourishing (DeVettere, 2002). In HRM terms, the use of practical wisdom is the ability to discern what needs to be carried out to flourish in organisations. In the case of HRM practitioners, the ability to evaluate alternatives, assess the normative impact on all agents and judge HRM practice against ethical and professional standards (see Table 1) seem important, particularly where existing principles and rules, as already mentioned, are not always clear.

As much as practical wisdom may provide alternatives regarding what to do, it also qualifies how HRM practitioners could choose to go about doing so. When we consider labour disputes, for example, from the perspective of practical wisdom, different alternatives may emerge. Human resource management practitioners may reason that in order for an organisation to flourish, excessive income differentials need to be addressed. The HRM practitioner may reason that one way to address income differentials is to increase the salaries of lower paid workers more in percentage terms than in comparison to their senior counterparts. Such an alternative could be seen as more important for organisational flourishing, than the principle of absolute equality of salary increase within the context of a particular organisation, and in terms of addressing worker vulnerability and historical disadvantage as being just.

Justice then is an interpersonal capability concerned with equity or fairness between people, or what Mele (2012) called 'relationability'. Morales-Sanchez and CabelloMedina (2015, p. S168) saw justice as a form of 'giving each one what they are due', which in HRM means at least respecting the rights of employees and applying standards and laws with impartiality. Concomitant behaviours include the search for what is appropriate and avoiding wrong doing, the willingness to correct own mistakes, the respect for the rights of people, the settling of conflicts equitably and the ability to apply standards taking into account special circumstances (Morales-Sanchez \& Cabello-Medina, 2015). The HRM practitioner then has a normative role in ensuring fairness in organisations and correcting past mistakes, which may require remediation such as in the case of affirmative action. 


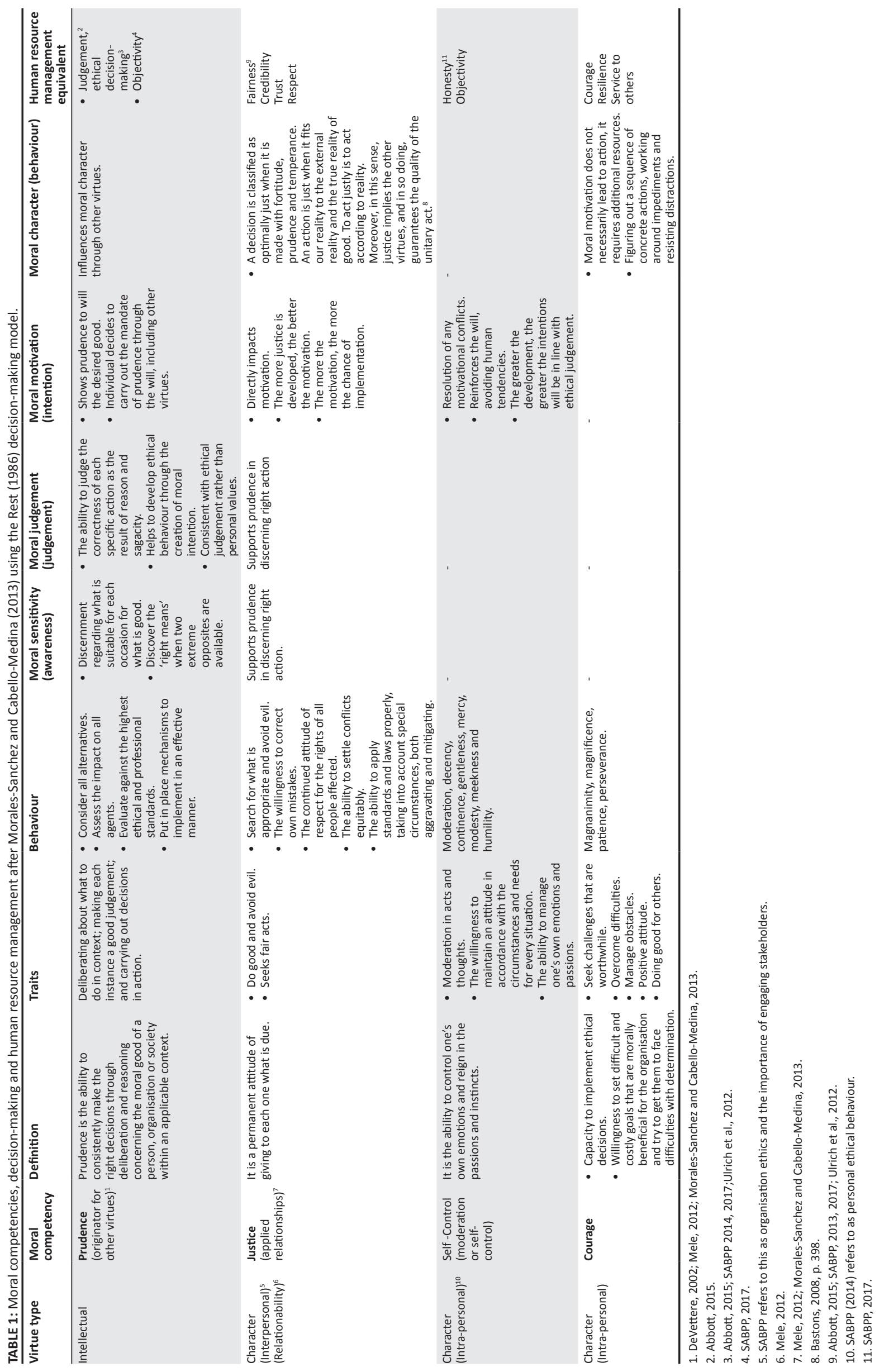


In contrast with justice, which has to do with the relations between people, self-control is an intrapersonal or 'character' virtue, which enables to 'control one's own emotions and dominate the passions and instincts' (MoralesSanchez \& Cabello-Medina, 2015, p. 169). Self-control is characterised by the behaviours of moderation, decency, gentleness, mercy, modesty and humility, amongst others, and could be described as a form of self-knowledge or personal maturity. A component of self-knowledge knows when to be humble in demonstrating expertise, how to be appropriately respectful to others, modest in success, calm during a crisis and able to control one's anger when provoked. Human resource management practitioners with self-knowledge also have more of a chance of avoiding personal bias and ensuring that their intentions remain in line with the required ethical judgement. For example, personal stakeholder bias could be avoided, which could be an over identification with management or enmity towards labour representatives.

The last of the cardinal virtues is courage. Similar to selfcontrol, courage is also an intrapersonal virtue. In our context, it is the 'willingness to set difficult and costly goals that are morally beneficial and face difficulties with determination' (Morales-Sanchez \& Cabello-Medina, 2015, p. S169). Examples of courage at the workplace include magnanimity, magnificence, patience and, importantly, perseverance, as it pertains to overcoming difficulties and doing good to others. Courage is also said to be an important part of the successful implementation of moral decisions (Morales-Sanchez \& Cabello-Medina, 2013). Human resource management practitioners with courage avoid diluting important moral goals because they are able to persevere and overcome moral obstacles that inevitably arise when pursuing such goals as equal pay for equal work for women, pursuing alternatives to retrenchments or resisting detrimental 'outsourcing' arrangements.

It seems then that there is normative value in using a virtuebased approach in HRM. The due consideration of the ethical implications of HRM practice and the skill to do so in the form of practical wisdom seems valuable. Furthermore, there is a depth to the normative account when an intelligent HRM response also includes (by definition) the other character virtues as named; be that justice, self-control and courage.

Up to now, the author has suggested and described different forms of HRM moral competence whilst providing some HRM examples of this skill. The question that remains is how in such a practitioner-focussed ethical approach, moral competence could be applied. Morales-Sanchez and CabelloMedina (2013) provided a virtue account of how moral competence could be used to improve normative outcomes through moral decision-making, which is described in more detail below in the context of HRM.

\section{Human resource management decision-making}

If HRM practitioners are practical experts in that they apply moral expertise such as practical wisdom with the aim of organisational flourishing, then how they go about using such expertise to make and implement ethical HRM decisions is important. Morales-Sanchez and Cabello-Medina (2013) described how professionals who are morally competent could use moral competence in different ways as they go through the various stages of decision-making, from moral awareness through to the implementation of such decisions. Such a moral competence in action approach is useful to begin with understanding how HRM practitioners could respond intelligently to HRM circumstances, be that in terms of motivation, agency and right action, as a form of HRM moral behaviour.

Morales-Sanchez and Cabello-Medina (2013) described how moral competence could be used during decision-making using Rest's (1986) four-stage decision-making model, which professionals such as HRM practitioners could use to improve normative outcomes. Rest's (1986) decision-making model has the following four stages: moral sensitivity, moral judgement, moral motivation and moral character. For each stage, Morales-Sanchez and Cabello-Medina (2013) described how moral competence could be applied. Table 1 summarises how practical wisdom, as a meta-virtue, contributes in different ways, to each stage of decision-making, as supported by the other cardinal virtues of justice, self-control and courage, as they pertain to HRM. I will now turn to the different stages in more detail as they pertain to HRM.

In the first stage of decision-making, HRM practitioners show moral sensitivity, when intentionally using practical wisdom to discern whether policy, process or behaviour, within a requisite context, 'is most convenient and suitable for each occasion, in accordance with the 'human good' (Morales-Sanchez and Cabello-Medina, 2013:724). The HRM practitioner begins to discern what could be correct for the situation and starts evaluating potential means towards correct action. This could involve the consideration of alternatives, assessing impact on others and the evaluation of the concerns against HRM standards (Morales-Sanchez \& Cabello-Medina, 2013).

Practical wisdom contributes significantly to moral judgement, which is the second stage of HRM decisionmaking. Practical wisdom at this stage is the skill to 'judge the correctness' of specific actions through reasoning and sagacity, regardless of personal values (Morales-Sanchez \& Cabello-Medina, 2013, p. 728). Human resource management practitioners assess the correctness of each act, morally labelling them, when considering all alternatives and their means. An important requirement of such consideration is also the technical expertise of an HRM practitioner. In the same way, a lawyer needs an understanding of the law or a 
doctor is skilled in medical procedure, a HRM practitioner also requires HRM technical competence in order to be able to consider all alternatives when responding in the context of the HRM domain.

The ability to make a moral judgement is not always sufficient to ensure that a correct action is taken. Practical wisdom contributes to the third stage of decision-making through what Morales-Sanchez and Cabello-Medina (2013, p. 728) called its imperative dimension. Over and above the cognitive ability for moral sensitivity and judgement, practical wisdom, as the name implies, also has a practical side, where 'decisions are seen as an imperative of the will' or what is called moral motivation or the third stage of decision-making. Human resource management practitioners often know the correct thing to do but fail to do so. For example, if an HRM practitioner judges that a labour dispute is based on unfair remuneration practices, then they cannot argue that this is a matter for the remuneration committee or ignore the issue in order to improve their own bonus position. If they have practical wisdom, they would be compelled to act.

It is at the third or the intentional stage of decision-making that the role of practical wisdom and its relationship with other cardinal virtues come up. Whilst practical wisdom commonly is seen to play a leading role in virtue theory and an important role in moulding the other virtues, the other cardinal virtues are also seen to support practical wisdom (DeVettere, 2002; Mele, 2012; Morales-Sanchez \& Cabello-Medina, 2013). Morales-Sanchez and Cabello-Medina (2013, p. 728) described how practical wisdom 'shows the desired good', which is then carried out by the 'individual through the will', exercising justice and 'avoid(ing) possible deviations' by using self-control and courage.

Finally, the resultant ethical behaviour (or character) is the fourth stage of normative agency. Rest (1986) saw ethical behaviour as the result of the judgements we make using our character much in the same way that moral competence results in intelligent responses in the virtue-as-skills approach. This involves turning moral judgement and motivation into the demonstration of moral behaviour. The resulting moral behaviour is a function of the unified nature of moral competence and is seen as excellent when judged by the criteria of justice (Bastons, 2008, p. 398) or the normative assessment of the impact it has on others.

It is conceivable then that practical experts broadly require expertise during decision-making, and more specifically moral expertise when making ethical judgements. Furthermore, moral expertise in the form of different types of virtues or moral skills operates together in different ways (as per the unity of the virtues) at different times or stages. The value of such an approach lies in how professional decision-making could be improved through the development of moral expertise, resulting in better normative outcomes. The author now develops this idea further by using the example of the moderation of performance ratings in HRM practice.

\section{Human resource management ethical practice}

Performance management, though important, remains controversial, as it goes to the heart of the use and recognition of employees in organisations. Performance management is commonly thought of as a 'planned process of directing, developing, supporting, aligning and improving individual and team performance in enabling the sustained achievement of organisational objectives' (SABPP, 2014, p. 67). In its many iterations, it is not the idea of performance management per se that is contested. Rather, the concern is whether it is fair for organisations to make decisions that affect individuals, such as in the case of personal development, promotions and remuneration, based on a process that is perceived to be inherently inconsistent in the way that it is implemented (Fletcher, 2001; Gibbon, 2015; Winstanley \& Stuart-Smith, 1996).

One of the processes that aim to improve consistency in performance management is the common HRM practice of moderating individual performance ratings. Moderation occurs when HRM practitioners, amongst others, align performance ratings against an idealised organisational performance curve after managers have assessed individual performance. Such moderation is seen as important mainly because of deficiencies in the capability of managers to rate effectively (Fletcher, 2001; Gibbon, 2015). However, do current conceptions of moderation meet the requirements of ethical HRM practice?

The dilemma is weighing up the perceived 'objectivity' of moderation with the impact on those individuals that end up overrated or underrated when not moderated. Employees are often sensitive to problems of overrating and underrating, though they also claim that moderation is not much better as it is carried out by those who do not know them, putting aside for the moment the issue of whether performance ratings in and of themselves are workable.

The situation regarding moderation is a complex one. Moderation is accepted and inherent in many HRM policies or guidelines as 'good HRM practice'. However, HRM practitioners are often made aware of employee dissatisfaction regarding moderation through feedback and grievances. Human resource management practitioners cannot merely rely or 'fall back' on accepted practice if the assumption of HRM moral competence holds. There is both strategic and normative value then to the HRM practitioner showing practical wisdom in being morally sensitive to employee concerns (stage 1).

The HRM practitioner may reason (stage 2) that moderation fails to recognise performance fairly because changes are made to performance ratings without the necessary knowledge of the individual, resulting in a lack of transparency and trust. As part of deliberating on moderation, the good HRM practitioner also requires technical capacity to evaluate potential HRM alternatives that may help resolve the dilemma. Such positive 
intersectionality is referred to as the coming together of hard (technical) and soft (normative) HRM or ethical convergences as a form of HRM practice (Carey, 1999).

The HRM practitioner may judge that it is better to change moderation from a model of instrumental or 'forced' altering of ratings to one of moderating the quality of management actions. Performance could be fairly recognised if managers actively engage with employees to set reasonable targets, ensure that employees have the capacity to perform and mutually agree on what has been achieved (Fletcher, 2001; Winstanley \& Stuart-Smith, 1996), conceivably obviating the need for moderation in the first place.

During deliberation, the HRM practitioner has to demonstrate the capacity for self-control, even though they may instinctively relate to managers and want to be able to control the outcomes of performance management. The capacity for self-control is important so that the development of justice (stage 3) is not inhibited and thereby the willingness or intention to act, ensuring that the resulting behaviour remains aligned to the moral intent. This then is the potential willingness to consider in this situation the alternatives that may challenge the quality and thereby the power of managers in the organisation.

Knowing what to do and being motivated to do so are insufficient to turn moral intent into moral action, which is the final stage of decision-making. If HRM practitioners want to moderate management actions, then courage is also required. Courage is required to hold managers accountable for their actions if the goal is the fair recognition of performance. The virtuous practitioner needs to maintain a positive attitude, demonstrating patience and resilience when confronting managers regarding their attitudes to performance and their capacity to engage and rate staff fairly. Furthermore, concrete actions are required to address and work around distractions, such as recalcitrant managers.

Moral competencies then operate together through the meta-competency of practical wisdom and contribute in various ways during the process of HRM decision-making. We have seen how - in the case of performance management - fair moderation could lead to better normative outcomes by having a positive impact on others, and how such moral competence in action could contribute to ethical HRM practice. Such ethical HRM practice has the potential to both question what is currently accepted as 'good HRM' and allow HRM practitioners to challenge, where necessary, the inherent power of stakeholders more effectively.

\section{Conclusion}

A case has been made for the importance of virtue as a skill in HRM in the form of moral competencies. Human resource management moral competence has the potential for the active moderation of interests within organisations using good judgement such as in our case of performance management. The advantage of such an approach to HRM decision-making is the potential for better normative outcomes and behaviour that is aligned to ethical intent. Such virtues as practical wisdom, justice, self-control and courage could form the basis of the professional character of HRM and furthermore a commitment to developing such skills.

\section{Acknowledgements}

The author is grateful to Prof. Dylan Futter, Department of Philosophy, University of the Witwatersrand, Johannesburg, for helping out with the research work.

\section{Competing interests}

The author has declared that no competing interests exist.

\section{Author(s) contributions}

I declare that I am the sole author of this research article.

\section{Funding information}

This research received no specific grant from any funding agency in the public, commercial or not-for-profit sectors.

\section{Ethical consideration}

This article followed all ethical standards for a research without direct contact with human or animal subjects.

\section{Data availability statement}

Data sharing is not applicable to this article as no new data were created or analysed in this study.

\section{Disclaimer}

The views and opinions expressed in this article are those of the author and do not necessarily reflect the official policy or position of any affiliated agency of the author.

\section{References}

Abbott, P.E. (2015). Ethical competence in HR management practice. Johannesburg: SABPP.

Academy of Human Resource Development (AHRD). (1999). Standards on ethics and integrity. Retrieved from https://www.ahrd.org/?standards_on_ethics

Annas, J. (1995). Virtue as a skill. International Journal of Philosophy Studies, 3(2), 227-243. https://doi.org/10.1080/09672559508570812

Annas, J. (2011). Intelligent virtue. Oxford: Oxford University Press.

Annas, J. (2015). Applying virtue to ethics (Society of Applied Philosophy Annual Lecture 2014). Journal of Applied Philosophy, 32(1), 1-14. https://doi.org/ 10.1111/japp.12103

Bastons, M. (2008). The role of virtues in the framing of decisions. Journal of Business Ethics, 78(3), 389-400. https://doi.org/10.1007/s10551-006-9332-x

Carey, L. (1999). Ethical dimensions of a strategic approach to HRM: An Australian perspective. Asia Pacific Journal of Human Resources, 37(3), 53-68. https://doi. org/10.1177/103841119903700305

Dahlsgaard, K., Peterson, C., \& Seligman, M.E.P. (2005). Shared virtue: The convergence of valued human strengths across culture and history. Review of General Psychology, 9(3), 203-213. https://doi.org/10.1037/1089-2680.9.3.203

Devettere, R.J. (2002). Introduction to virtue ethics: Insights of the ancient Greeks. Washington, DC: Georgetown University Press. 
Fletcher, C. (2001). Performance appraisal and management: The developing research agenda. Journal of Occupational and Organizational Psychology, 74(4), 473-487. https://doi.org/10.1348/096317901167488

Gibbon, P. (2015). Ethics in performance management. In P. Abbott (Ed.), Ethical competence in HR management practice (pp. 169-179), Johannesburg: SABPP.

Greenwood, M. (2002). Ethics and HRM: A review and conceptual analysis. Journal of Business Ethics, 36, 261-278. https://doi.org/10.1023/A:1014090411946

Hursthouse, R. (1991). Virtue theory and abortion. Philosophy \& Public Affairs, 20(3), 223-246.

Hursthouse, R. (2013). Virtue ethics. In Stanford encyclopaedia of philosophy Retrieved from http://plato.stanford.edu/archives/fall2013/entries/ethicsvirtue/

Kirsten, M., Wordsworth, R., VanNiekerk, M., \& Erasmus, B. (2015). Are we there yet? The role of HR in promoting ethical behaviour: 2002-2014. In P. Abbot (Ed.) Ethical competence in HR management practice (pp. 15-29), Johannesburg: SABPP.

Lee, E., \& Yu, K.S. (2013). How are global HR competency models evolving for the future? Ithaca, NY: ILR School, Cornell University. Retrieved from http:// digitalcommons.ilr.cornell.edu/student/17/

Mele, D. (2012). Management ethics. Placing ethics at the core of good management. Hampshire: Palgrave Macmillan.

Morales-Sanchez, R., \& Cabello-Medina, C. (2013). The role of four universal moral competencies in ethical decision-making. Journal of Business Ethics, 116 717-734.

Morales-Sanchez, R., \& Cabello-Medina, C. (2015). Integrating character in management: Virtues, character strengths, and competencies. Journal of Business Ethics: A European Review, 24(S2), 156-174. https://doi.org/10.1111/ beer.12104
Rest, J.R. (1986). Moral development: Advances in research and theory. New York, NY: Praeger.

Society for Human Resource Management (SHRM). (2012, 2016). The SHRM competency model. Retrieved from https://www.shrm.org/learningandcareer/ competency-model/pages/default.aspx

South African Board of People Practices (SABPP). (2014). National human resource management standards. HRM file provided to SABPP, Johannesburg: SABPP.

South African Board of People Practices (SABPP). (2017). HR standards update, HR professional practice standards, SABPP. HRM publication provided to SABPP, Johannesburg: SABPP.

Stichter, M. (2007a). Ethical expertise: The skill model of virtue. Ethical Theory and Moral Practice, 10, 183-194. https://doi.org/10.1007/s10677-006-9054-2

Stichter, M. (2007b). The skill of virtue. Dissertation submitted to the Graduate College of Bowling Green State University, Bowling Green, Ohio.

Stichter, M. (2013). Virtue as skills in virtue epistemology. Pre-print draft. Journal of Philosophical Research, 38, 333-348. https://doi.org/10.5840/jpr20133817

Stichter, M. (2015). Practical skills and practical wisdom in virtue. Australasian Journal of Philosophy, 94(3), 435-448. https://doi.org/10.1080/00048402.2015. 1074257

Ulrich, D., Younger, J., Brockbank, W., \& Ulrich, M. (2012). HR from the Outside In, Six Competencies for the Future of Human Resources, New York: McGraw Hill.

Van Vuuren, L.J., \& Eiselen, R.J. (2006). A role for HR in corporate ethics? South African practitioners' perspectives. South African Journal of Human Resource Management 4(3), 22-28. https://doi.org/10.4102/sajhrm.v4i3.95

Winstanley, D. \& Stuart-Smith, K. (1996). Policing performance: The ethics of performance management. Personnel Review, 25(6), 66-84. https://doi.org/ $10.1108 / 00483489610148545$ 